\title{
Production of Biodiesel Feedstock by Integrated Growth of Isolated Oleaginous Yeast and Microalgae
}

\author{
Rattanaporn Baojungharn, Mutiyaporn Paungbut, Supaporn Kookkhunthod, and Ratanaporn Leesing
}

\begin{abstract}
The oleaginous microalgae and yeasts have been suggested as a promising biodiesel feedstock because of their potential for lipid production under various mode of cultivation. In this study, microbial biomass and lipid production to use as biodiesel feedstock by microalgae Chlorella sp. KKU-S2 and yeast TorulasporaglobosaYU5/2 via integrated cultivation technique using $\mathrm{CO}_{2}$ emissions from yeast cultivation as inorganic carbon source for mixotrophic growth of microalgae were investigated. A maximum specific growth rate of Chlorella sp. KKU-S2 of $0.380(1 / d)$ was obtained via integrated growth using $\mathrm{CO}_{2}$ emissions from yeast $T$.globosaYU5/2 grown on molasses while specific growth rate of $0.219(1 / \mathrm{d})$ was found via non-integrated growth. A high value of lipid productivity $\left(Q_{P}\right.$, $0.338 \mathrm{~g} / \mathrm{L} / \mathrm{d})$, specific product yield $\left(Y_{P / X}, 0.202\right)$, biomass productivity $\left(Q_{X}, 1.633 \mathrm{~g} / \mathrm{L} / \mathrm{d}\right)$ of Chlorella sp. KKU-S2 were found by integrated growth with T.globosaYU5/2 cultivation on molasses, overall biomass and lipid yield of $17.71 \mathrm{~g} / \mathrm{L}$ and $2.89 \mathrm{~g} / \mathrm{L}$ was obtained, respectively. To our knowledge there are a few reports about the microbial biomass and microbial lipid production from isolated microalgae Chlorella sp. KKU-S2 and isolated yeast T.globosaYU5/2in an integrated technique by using $\mathrm{CO}_{2}$ emissions from yeast cultivation.
\end{abstract}

Index Terms-Microbial lipid, biodiesel feedstock, microalgae, oleaginous yeast, integrated cultivation.

\section{INTRODUCTION}

Microbial oils, lipid produced from oleaginous microorganisms involving yeasts, moulds, and microalgae, which have ability to accumulate lipids over $20 \%$ of their biomass, are considered as the third generation of biodiesel feedstock due to some advantages such as short production period, higher biomass production and faster growth compared to other energy crops, easiness to scale up [1], [2]. Microalgae have the highest oil or lipid yield among various plant oils, and the lipid content of some microalgae has up to $80 \%$ and the compositions of microalgallipids are mainly triglyceride which is the right kind of oil for producing biodiesel [2].

Manuscript received September 25, 2014; revised July 20, 2015. This work was supported by the Higher Education Research Promotion and National Research University (NRU) Project of Thailand, Office of the Higher Education Commission, through the Biofuel Cluster of Khon Kaen University and Khon Kaen University (KKU) Research Fund, fiscal years 2011-2012. Grant for traveling support from Graduate School of Khon Kaen University is gratefully acknowledged.

Rattanaporn Baojungharn, Mutiyaporn Paungbut, and Supaporn Kookkhunthodare are with the Graduate School of Khon Kaen University, Khon Kaen 40002, Thailand (e-mail: birdjidrid@windowslive.com, mutiyapornp@kkumail.com, supaporn.kookkhunthod.mam@gmail.com).

Ratanaporn Leesing is with the Department of Microbiology, Faculty of Science, Alternative Energy Research and Development (AERD) and Fermentation Research Center for Value Added Agricultural Products (FerVAAP), Khon Kaen University, Khon Kaen 40002, Thailand (e-mail: ratlee@kku.ac.th).
Microalgae may assume many types of metabolisms, such as photoautotrophic, heterotrophic and mixotrophic growths [3]. In photoautotrophic growth, the sole energy source for biomass production is light energy and the sole carbon source is inorganic compounds especially carbon dioxide $\left(\mathrm{CO}_{2}\right)$.

Compared to autotrophic cultivation, heterotrophic and mixotrophic cultivations allow some microalgae to provide high biomass and lipid productivity [4]-[6] Mixotrophic growth of microalgae have an edge over photoautotrophic growth as they have two energy sources as organic carbon source and light, they can simultaneously drive photoautotrophic and heterotrophic to utilize both inorganic (as $\mathrm{CO}_{2}$ ) and organic carbon substrates, therefore, microalgae cultivated under mixotrophic culture synthesize compounds characteristic at high production rates of both photosynthetic and heterotrophic metabolisms of organic substrates are independent of each other [3], [7]. It was reported that only few microalgae can be cultivated mixotrophically such as Haematococcuspluvialis, Chlorellaprotothecoides, Chlorella sp. KKU-S2 [8], [9].

$\mathrm{CO}_{2}$ as a nutrient represents one of the most costly components in the cultivation of microalgae. Therefore a system that couples a waste $\mathrm{CO}_{2}$ source with the cultivation of $\mathrm{CO}_{2}$ fixing microalgae can not only reduce cultivation costs but also mitigate or remove $\mathrm{CO}_{2}$, greenhouse gas (GHG) as an environmental pollution. Waste $\mathrm{CO}_{2}$ can be provided by using $\mathrm{CO}_{2}$ emissions from agro-industrial plants such as the ethanol fermentation by yeast [10].

Oleaginous yeasts are capable of accumulating large amounts of cellular lipids and it also has a high growth rate and some strains can accumulate intracellular lipids to level exceeding $70 \%$ of their biomass under nutrient limitation condition [11]. Lipid production from yeast cultivation produces $\mathrm{CO}_{2}$ which can be provided for mixotrophic growth of microalgae by using an integrated culture technique that incorporates both $\mathrm{CO}_{2}$ consumption and microbial lipid production appear to be the best approach to enable industrial application of these new technologies for environmental benefit. Therefore, the main aim of this study is to investigate the production of microbial lipid via integrated growth of yeast T. globosaYU5/2 and microalgae Chlorella sp. KKU-S2.

\section{MAteriaLS AND MethodS}

\section{A. Carbon Substrate, Microorganisms and Culture Conditions}

The carbon substrates used in this study were sugarcane juice (S), sugarcane molasses (M) and sweet potato tubers collected from a local market in Khon Kaen province, Thailand. The sweet potato powder was mixed with 
hydrochloric acid for final concentration of $2 \%(\mathrm{v} / \mathrm{v})$, and then treated in water baht at $100^{\circ} \mathrm{C}$ for $20 \mathrm{~min}$. After cooling, the liquid fraction as sweet potato hydrolysate $(\mathrm{P})$ was separated by centrifugation to remove insoluble particles then neutralized by adding $5 \mathrm{~N} \mathrm{NaOH}$ and stored at $4{ }^{\circ} \mathrm{C}$ prior to use.

The oleaginous yeasts TorulasporaglobosaYU5/2used in this study was isolated from soil samples taken from forest in the area of Chaiyapoom Province, Thailand [12]. Active cultures for inoculation were obtained in $500 \mathrm{~mL}$ Erlenmeyer flasks with $200 \mathrm{~mL}$ of growth medium containing $20 \mathrm{~g} / \mathrm{L}$ glucose, $20 \mathrm{~g} / \mathrm{L}$ peptone, and $10 \mathrm{~g} / \mathrm{L}$ yeast extract. The seed cultures were cultivated onto yeast medium supplemented with $20 \mathrm{~g} / \mathrm{L}$ glucose at $30^{\circ} \mathrm{C}$ in rotary shaker at $150 \mathrm{rpm}$ for 1 day. The yeast medium was consisted of $(\mathrm{g} / \mathrm{L}):\left(\mathrm{NH}_{4}\right)_{2} \mathrm{SO}_{4}$ $0.1, \mathrm{KH}_{2} \mathrm{PO}_{4} 0.4, \mathrm{MgSO}_{4} .7 \mathrm{H}_{2} \mathrm{O} 1.5, \mathrm{ZnSO}_{4} 0.0044, \mathrm{CaCl}_{2}$ $0.0025, \mathrm{MnCl}_{2} 0.0005, \mathrm{CuSO}_{4} 0.0003$ and yeast extract 0.75 , initial $\mathrm{pH}$ was adjusted to 5.0-5.5.

The microalgae Chlorella sp. KKU-S2 used in this study was isolated from freshwater taken from pond in the area of Khon Kaen province, Thailand [7]. Active cultures for inoculation were obtained in $500 \mathrm{~mL}$ Erlenmeyer flasks with $200 \mathrm{~mL}$ of Bristol's medium supplemented with $20 \mathrm{~g} / \mathrm{L}$ glucose. The seed culture was cultivated onto Bristol's medium containing $20 \mathrm{~g} / \mathrm{L}$ glucose at $30^{\circ} \mathrm{C}$ in rotary shaker at $150 \mathrm{rpm}$ for 3 days and continuous illuminated from overhead by $80 \mathrm{~W}$ cool-white fluorescent lamps. The Bristol's medium was consisted of $(\mathrm{mg} / \mathrm{L}): \mathrm{NaNO}_{3} 250$, $\mathrm{K}_{2} \mathrm{HPO}_{4} 75, \mathrm{KH}_{2} \mathrm{PO}_{4} 175, \mathrm{CaCl}_{2} 25, \mathrm{NaCl} 25, \mathrm{MgSO}_{4} .7 \mathrm{H}_{2} \mathrm{O}$ 75 , and $\mathrm{FeCl} 20.3, \mathrm{MnSO}_{4} \cdot 2 \mathrm{H}_{2} \mathrm{O} 0.3, \mathrm{ZnSO}_{4} 7 \mathrm{H}_{2} \mathrm{O} 0.2$, $\mathrm{H}_{3} \mathrm{BO}_{3} 0.2, \mathrm{CuSO}_{4} .5 \mathrm{H}_{2} \mathrm{O} 0.06$, and initial $\mathrm{pH}$ was adjusted to 6.0-6.5.

\section{B. Microbial Oil Production by Integrated Cultivation Technique for Lipid Production}

Cultivation of each strain was performed in $4000 \mathrm{~mL}$ Erlenmeyer flask with a working volume of $2000 \mathrm{~mL}$. Yeast $T$. globosaYU5/2 was cultivated onto LA medium containing of different types of carbon substrate as sugarcane juice $(\mathrm{S})$, sugarcane molasses $(\mathrm{M})$ and sweet potato hydrolysate $(\mathrm{P})$ with $20 \mathrm{~g} / \mathrm{L}$ of reducing sugar and $1.0 \mathrm{~g} / \mathrm{L}$ yeast extract as nitrogen source at ambient temperature under continuous agitation. The microalgae Chlorella sp. KKU-S2 was cultivated onto Bristol's medium containing $20 \mathrm{~g} / \mathrm{L}$ glucose and $1.0 \mathrm{~g} / \mathrm{LNaNO}_{3}$ as nitrogen source with $10 \%(\mathrm{v} / \mathrm{v})$ seed culture of each strain and incubated at ambient temperature under continuous illumination by using $80 \mathrm{~W}$ cool-white fluorescent lamps. The $\mathrm{CO}_{2}$ produced by the yeast cultivation is split and connected directly into the surrounding microalgae flask for mixotrophic growth (Fig. 1). To comparison of growth and lipid production, cultivation of microalgae was investigated without the addition of $\mathrm{CO}_{2}$ emissions from yeast $T$. globosaYU5/2 cultivation.

\section{Analytical Methods}

Cell growth of Chlorella sp. KKU-S2 and $T$. globosa YU5/2 were determined by optical density reading at $680 \mathrm{~nm}\left(\mathrm{OD}_{680}\right)$ and $660 \mathrm{~nm}\left(\mathrm{OD}_{660}\right)$, respectively. A standard curve was prepared by plotting dry cell weight (DCW) values $(\mathrm{g} / \mathrm{L})$ against corresponding optical density $\left(\mathrm{OD}_{680}\right)$ readings by using spectrophotometer.

A linear regression fit was obtained for dry cell weight
(DCW) of Chlorella sp. KKU-S2 as a function of $\mathrm{OD}_{680}, y=$ $1.9039 x+2.2149, R^{2}=0.9964$, and that linear regression fit of T. globosaYU5/2 as a function of $\mathrm{OD}_{660}, y=$ $2.9886 x+0.5627, R^{2}=0.9948$. There was a direct correlation between optical density and dry cell weight.

The culture broth was centrifuged at 5,000 rpm for $5 \mathrm{~min}$ then the supernatant was analyzed for reducing sugar concentration according to DNS method [13]. Cellular lipids were determined by the modified method of Kwon and Rhee [14]. Biomass and Lipid productivities were calculated.

Biomass productivity $\left(Q_{X}, \mathrm{~g} / \mathrm{L} / \mathrm{d}\right)$ during the culture period was calculated; $Q_{X}=\left(X_{t}-X_{0}\right) /\left(t_{t}-t_{0}\right)$, where $X_{t}$ was the biomass concentration $(\mathrm{g} / \mathrm{L})$ at the end of growth phase $\left(t_{t}\right)$ and $X_{0}$ the initial biomass concentration $(\mathrm{g} / \mathrm{L})$ at $t_{0}$ (day).

Lipid productivity $\left(Q_{P}, \mathrm{~g} / \mathrm{L} / \mathrm{d}\right)$ at the end of cultivation was calculated: $Q_{P}=\left(P_{t}-P_{0}\right) /\left(t_{t}-t_{0}\right)$, where $P_{t}$ was the lipid yield $(\mathrm{g} / \mathrm{L})$ at the end of growth phase $\left(t_{t}\right)$ and $P_{0}$ the initial lipid yield $(\mathrm{g} / \mathrm{L})$ at $t_{0}$ (day). Specific product yield $\left(Y_{P / X}\right)$ was determined using relationship $\mathrm{d} P / \mathrm{d} X$.

The specific growth rate $(\mu)$ is the slope determined by plotting the natural log of biomass versus time for each substrate concentration during the initial phase of exponential growth before the substrate concentration decreases significantly while specific rate of lipid production $\left(q_{P}\right)$ was a multiple of $\mu$ and $Y_{P / X}$.
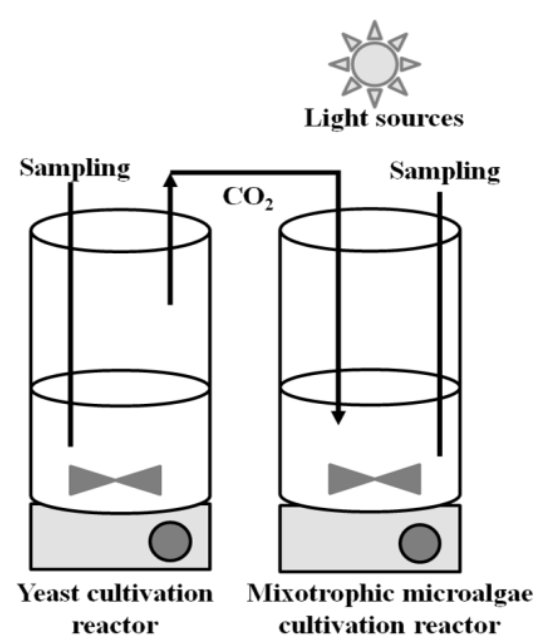

Fig. 1. Simplified schematic of yeast T. globosaYU5/2 cultivation and mixotrophic microalgae Chlorella sp. KKU-S2 cultivation for microbial biomass and lipid production, cultivated at ambient temperature under continuous illuminated with $80 \mathrm{~W}$ cool-white fluorescent lamps.

\section{RESULTS AND DISCUSSION}

Batch cultivation of yeast $T$. globosaYU5/2 was cultivated on culture medium supplemented with different types of carbon substrate as sugarcane juice $(\mathrm{S})$, sugarcane molasses (M) and sweet potato hydrolysate $(\mathrm{P})$ with initial reducing sugar of $20 \mathrm{~g} / \mathrm{L}$. After cultivation for 6 days, a biomass and lipid yield reached the maximum of $8.08 \mathrm{~g} / \mathrm{L}$ with biomass productivity of $1.347 \mathrm{~g} / \mathrm{L} / \mathrm{d}$ and $0.970 \mathrm{~g} / \mathrm{L}$ with lipid productivity of $0.153 \mathrm{~g} / \mathrm{L} / \mathrm{d}$ were obtained from yeast $T$. globosaYU5/2 grown on sugarcane juice (S) (Fig. 2 and Table I). Waste $\mathrm{CO}_{2}$ produced by the cultivation of yeast $T$. globosaYU5/2 during lipid production, is connected directly into the surrounding microalgae flask and combined with ambient air for mixotrophic growth of Chlorella sp. KKU-S2. 
As shown in Fig. 3, there are significant different of optical density $\left(\mathrm{OD}_{680}\right)$ changes observed in the growth of microalgae during cell growth with different sources of $\mathrm{CO}_{2}$, higher value of $\mathrm{OD}_{680}$ of 22.80 was obtained by cultivation of microalgae by integrated growth with couple- $\mathrm{CO}_{2}$ emissions from yeast cultivation on molasses for 6days than that of the cultivation by integrated with yeast cultivation on sugarcane juice and sweet potato hydrolysate. The $\mathrm{OD}_{680}$ of 8.65 was obtained by non-integrated growth of Chlorella sp. KKU-S2.

A maximum biomass and lipid yield of Chlorella sp. KKU-S2 was obtained via integrated growth using $\mathrm{CO}_{2}$ emissions from yeast grown on molasses (KKU-S2 (M)), a biomass of $9.80 \mathrm{~g} / \mathrm{L}$ with biomass productivity of $1.633 \mathrm{~g} / \mathrm{L} / \mathrm{d}$ and lipid yield of $1.980 \mathrm{~g} / \mathrm{L}$ with lipid productivity $0.633 \mathrm{~g} / \mathrm{L} / \mathrm{d}$, while a biomass of $3.72 \mathrm{~g} / \mathrm{L}$ with biomass productivity of was found via non-integrated growth of Chlorella sp. KKU-S2 (Table I).

In case of integrated cultivation process, overall lipid yield of $2.89 \mathrm{~g} / \mathrm{L}$ was obtained as $0.910 \mathrm{~g} / \mathrm{L}$ of $T$. globosa YU5/2 and $1.980 \mathrm{~g} / \mathrm{L}$ of Chlorella sp. KKU-S2, while only $0.410 \mathrm{~g} / \mathrm{L}$ of lipid yield was found from Chlorella sp. KKU-S2 via non-integrated growth technique. The integration of the mixotrophic microalgae cultivation systems into an existing yeast cultivation system is made economically feasible by the production of two new revenue streams as microbial lipid from microalgae and oleaginous yeast for used as biodiesel feedstock and the capture of $\mathrm{CO}_{2}$ emissions from the yeast cultivation stage [7], [10].

TABLE I: KINETIC PARAMETERS OF INTEGRATED GROWTH OF T. GLOBOSA YU5/2 ON LiPID ACCUMULATION MEDIUM SUPPLEMENTED WITH MOLASSES (M),

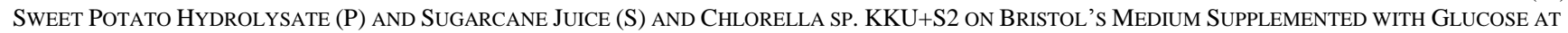
DAY 6 OF CUlTiVATION TIME AT AMBIENT TEMPERATURE, 150 RPM.

\begin{tabular}{|c|c|c|c|c|c|c|c|}
\hline \multirow[b]{2}{*}{ Culture conditions } & \multicolumn{7}{|c|}{ Kinetic parameters } \\
\hline & $\begin{array}{c}X \\
(g / L)\end{array}$ & $\begin{array}{c}P \\
(g / L)\end{array}$ & $\begin{array}{c}Q_{X} \\
(\mathrm{~g} / \mathrm{L} \mathbf{d})\end{array}$ & $\begin{array}{c}Q_{P} \\
(\mathrm{~g} / \mathrm{L} \mathrm{d})\end{array}$ & $\begin{array}{c}\mu \\
(1 / d)\end{array}$ & $Y_{P / X}$ & $q_{P}$ \\
\hline T. globosa YU5/2 (YU52 M) & 7.91 & 0.910 & 1.318 & 0.152 & 0.345 & 0.115 & 0.040 \\
\hline T. globosa YU5/2 (YU52 P) & 8.08 & 0.970 & 1.347 & 0.162 & 0.348 & 0.146 & 0.051 \\
\hline T. globosa YU5/2 (YU52 S) & 3.81 & 0.410 & 0.635 & 0.068 & 0.223 & 0.108 & 0.024 \\
\hline Chlorella sp. KKU-S2-integrated with YU52 (M) & 9.80 & 1.980 & 1.633 & 0.330 & 0.380 & 0.202 & 0.077 \\
\hline Chlorella sp. KKU-S2-integrated with YU52 (P) & 5.33 & 0.780 & 0.888 & 0.130 & 0.279 & 0.120 & 0.033 \\
\hline Chlorella sp. KKU-S2-integrated with YU52 (S) & 5.85 & 0.920 & 0.975 & 0.153 & 0.294 & 0.157 & 0.046 \\
\hline Chlorella sp. KKU-S2 (non-integrated, control) & 3.72 & 0.410 & 0.620 & 0.068 & 0.219 & 0.110 & 0.024 \\
\hline
\end{tabular}
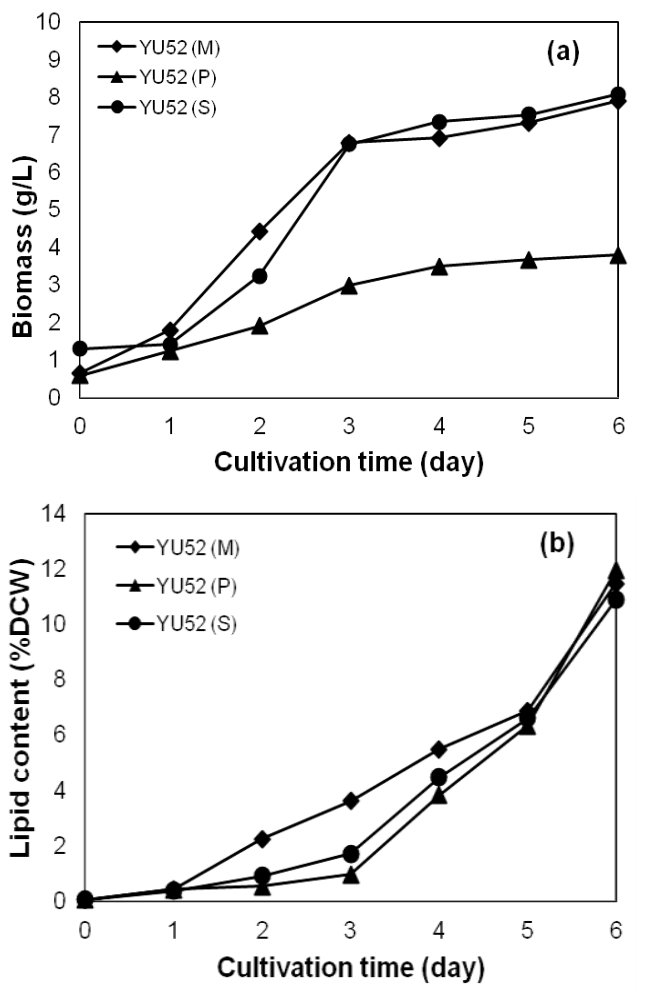

Fig. 2. Biomass yield (a) and lipid yield (b) during cultivation of T.globosaYU5/2 on lipid accumulation medium supplemented with molasses $(\mathrm{M})$, sweet potato hydrolysate $(\mathrm{P})$ and sugarcane juice $(\mathrm{S})$ as carbon substrate with $20 \mathrm{~g} / \mathrm{L}$ reducing sugar, incubated at ambient temperature, 6 days.

There are significant different of lipid productivity $\left(Q_{P}\right)$, specific product yields $\left(Y_{P / X}\right)$, biomass productivity $\left(Q_{X}\right)$ and specific rate of lipid production $\left(q_{P}\right)$ by using integrated

growth techniques. A high value of all parameters was found when using $\mathrm{CO}_{2}$ emissions from yeast cultivation for supported the growth and lipid production of microalgae Chlorella sp. KKU-S2. Similarly, Scenedesmusobliquus and Chlorella kessleri showed a particularly high potential for bio-fixation of $\mathrm{CO}_{2}$ [15].
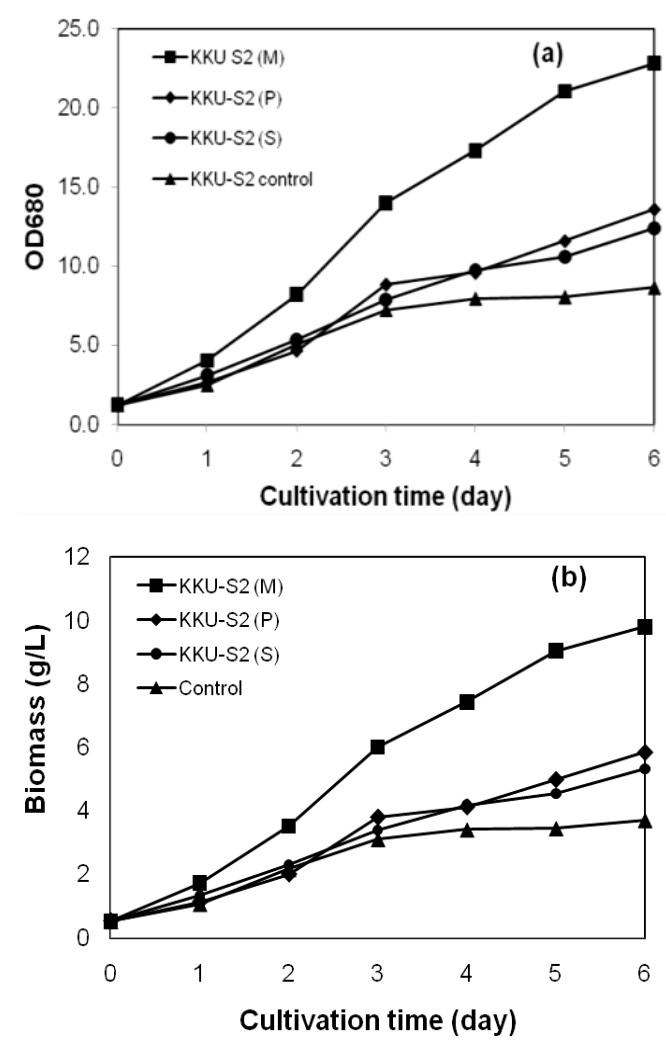


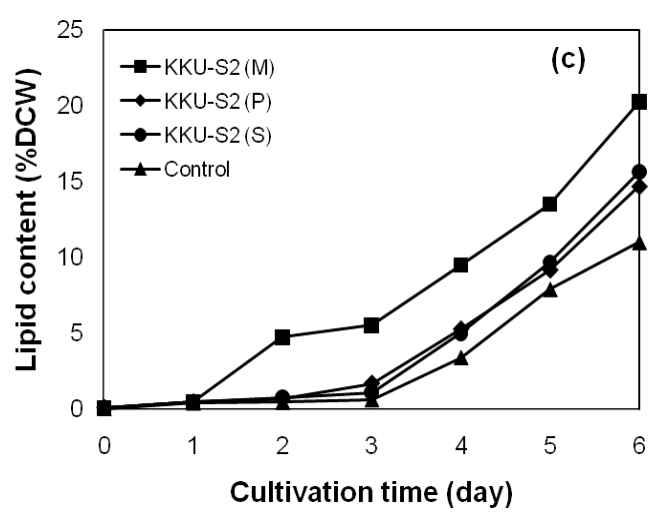

Fig. 3. Optical density (OD680) (a), biomass yield (b) and lipid yield (c) of Chlorella sp. KKU-S2 on Bristol's medium containing 20g/L glucose under mixotrophic cultivation via integrated growth by using $\mathrm{CO}_{2}$ emitted from $T$. globosaYU5/2 cultivation with molasses (KKU-S2(M)), sweet potato hydrolysate (KKU-S2(P)) and sugarcane juice (KKU-S2(S)) as carbon substrate and non-integrated growth without $\mathrm{CO}_{2}$ coupled from $\mathrm{CO}_{2}$ emitted from yeast (control), incubated at ambient temperature, 6 days.

\section{CONCLUSIONS}

In conclusion, we present an integrated growth and microbial oil production of yeast and microalgae. To our knowledge this is the unique report about the microbial lipid production from isolated microalgae Chlorella sp. KKU-S2 under mixotrophic growth and oleaginous yeast $T$. globosaYU5/2in an integrated technique to improve the biomass and lipid productivity by using $\mathrm{CO}_{2}$ emissions from yeast cultivation suggesting to reduce cultivation costs and also remove and value-added of $\mathrm{CO}_{2}$, greenhouse gas, this process could be so called that environmental friendly process. This cultivation method will open new perspectives in the production of microbial biomass and microbial oil which could be used as potential feedstock for biodiesel production. In further works, conversion of oil contained-microbial biomass to biodiesel as fatty acid methyl ester (FAME) by direct transesterification, characteristics and quality of FAME will be investigated.

\section{REFERENCES}

[1] X. Meng, J. Yang, X. Xu, L. Zhang, Q. Nie, and M. Xian, "Biodiesel production from oleaginous microorganisms," Renewable Energy, vol. 34, pp. 1-5, 2009.

[2] A. L. Ahmad, N. H. M. Yasin, C. J. C. Derek, and J. K. Lim, "Microalgae as a sustainable energy source for biodiesel production: A review," Renewable and Sustainable Energy Reviews, vol. 15, pp. 584-593, 2011

[3] T. Ogawa and S. Aiba, "Bioenergetic analysis of mixotrophic growth in Chlorella vulgaris and Scenedesmusacutus," Biotechnol. Bioeng., vol. 23, pp. 1121-1132, 1981.

[4] X. Miao and Q. Wu, "Biodiesel production from heterotrophic microalgal oil," Bioresour. Technol., vol. 97, pp. 841-846, 2006.

[5] X. Li, H. Xu, and Q. Wu, "Large-scale biodiesel production from microalga Chlorella protothecoides through heterotrophic cultivation in bioreactors," Biotechnol. Bioeng., vol. 98, pp. 764-771, 2007.

[6] S. J. Yoo, J. H. Kim, and J. M. Lee, "Dynamic modelling of mixotrophic microalgal photo bioreactor systems with time-varying yield coefficient for the lipid consumption," Bioresource Technology, vol. 162, pp. 228-235, 2014.

[7] T. Heredia-Arroyo, W. Wei, R. Ruan, and B. Hu, "Mixotrophic cultivation of Chlorellavulgaris and its potential application for the oil accumulation from non-sugar materials," Biomass Bioenergy, vol. 35, pp. 2245-2253, 2011.
[8] Y. Liang, N. Sarkany, and Y. Cui, "Biomass and lipid productivities of Chlorella vulgaris under autotrophic, heterotrophic and mixotrophic growth conditions,"Biotechnol. Lett., vol. 31, pp.1043-1049, 2009.

[9] R. Leesing and N. Nontaso, "Microalgal oil production by green microalgae under heterotrophic cultivation," KKU Res J., vol. 9, pp. 787-793, 2010.

[10] E. E. Powell and G. A. Hill, "Economic assessment of an integrated bioethanol-biodiesel-microbial fuel cell facility utilizing yeast and photosynthetic algae," ChemEng Res Design, vol. 87, pp. 1340-1348, 2009.

[11] O. Tehlivets, K. Scheuringer, and S. D. Kohlwein, "Fatty acid synthesis and elongation in yeast," Biochimicaet Biophysica Acta, vol. 1771, pp. 255-270, 2007.

[12] R. Leesing and P. Karraphan, "Kinetic growth of the isolated oleaginous yeast for lipid production," African J. Biotechnol, vol. 63, pp. 13867-13877, 2011.

[13] G. L. Miller, "Use of dinitrosalicylic acid reagent for determination of reducing sugar," Anal Chem., vol. 31, pp. 426-432, 1959.

[14] D. Y. Kwon and J. S. Rhee, "A Simple and rapid colorimetric method for determination of free fatty acids for lipase assay," $\mathrm{J} \mathrm{Am}$ Oil ChemSoc, vol. 63, pp. 89-92, 1986.

[15] S. Y. Chiu, C. Y. Kao, C. H. Chen, T. C. Kuan, S. C. Ong, and C. S. Lin, "Reduction of $\mathrm{CO}_{2}$ by a high density culture of Chlorella sp. in a semi-continuous photo bioreactor," Bioresour Technol., vol. 99, pp. 3389-3396, 2008

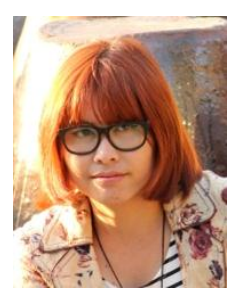

Rattanaporn Baojungharn received her bachelor of science degree in microbiology from Khon Kaen University, Khon Kaen, Thailand. She is now a master student at the Department of Microbiology, Faculty of Science, Khon Kaen University, Thailand. Her research interest for master study is production of biomass and lipid from the oleaginous yeast and biodiesel preparation from microbial oil.

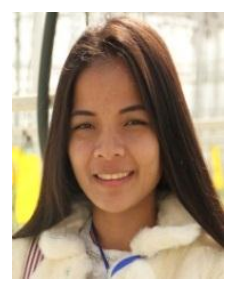

Mutiyaporn Paungbut obtained her bachelor of science degree in biology from Mahasarakham University, Mahasarakham, Thailand. She received her mater degree of science in microbiology from Khon Kaen University, Thailand. She is now a Ph.D. student at the Department of Microbiology, Faculty of Science, Khon Kaen University Thailand. Her research interest for Ph.D. is cultivation of mixed culture of microalgae and yeast and conversion of microbial biomass to biodiesel fuel.

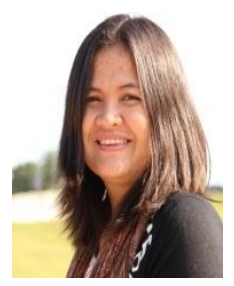

Supaporn Kookkhunthod got her bachelor of science degree in microbiology from Khon Kaen University, Khon Kaen, Thailand. Currently she is a master degree student at the Department of Microbiology, Faculty of Science, Khon Kaen University, Khon Kaen, Thailand. Her master research study area is focusing on cultivation of microalgae for biomass and lipid production and microalgae-based biodiesel production.

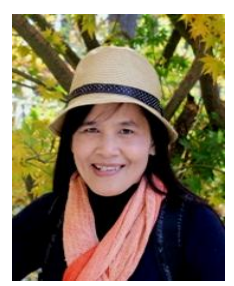

Ratanaporn Leesing is an assistant professor in the Department of Microbiology, Faculty of Science, Khon Kaen University, Khon Kaen, Thailand. She obtained the B.Sc. degree in biology-microbiology from Khon Kaen University, Khon Kaen, Thailand She received the M.Sc. degree in biotechnology from King Mongkut's University of Technology Thonburi, Bangkok, Thailand and graduated with a Ph.D. degree in food sciences from the University of Montpellier II, Montpellier, France. Her recent research interest and teaching activities are in the field of bio-resources, bio-energy and fermentation technology. 


\section{Electrical Energy}


